\title{
Genome-wide identification of sucrose nonfermenting-1-related protein kinase (SnRK) genes in barley and RNA-seq analyses of their expression in response to abscisic acid treatment
}

\author{
Zhiwei Chen ${ }^{1,2+}$, Longhua Zhou ${ }^{1,2 \dagger}$, Panpan Jiang ${ }^{3}$, Ruiju Lu ${ }^{1,2}$, Nigel G. Halford ${ }^{4}$ and Chenghong Liu ${ }^{1,2^{*}}$ (1)
}

\begin{abstract}
Background: Sucrose nonfermenting-1 (SNF1)-related protein kinases (SnRKs) play important roles in regulating metabolism and stress responses in plants, providing a conduit for crosstalk between metabolic and stress signalling, in some cases involving the stress hormone, abscisic acid (ABA). The burgeoning and divergence of the plant gene family has led to the evolution of three subfamilies, SnRK1, SnRK2 and SnRK3, of which SnRK2 and SnRK3 are unique to plants. Therefore, the study of SnRKs in crops may lead to the development of strategies for breeding crop varieties that are more resilient under stress conditions. In the present study, we describe the SnRK gene family of barley (Hordeum vulgare), the widespread cultivation of which can be attributed to its good adaptation to different environments.

Results: The barley HvSnRK gene family was elucidated in its entirety from publicly-available genome data and found to comprise 50 genes. Phylogenetic analyses assigned six of the genes to the HvSnRK1 subfamily, 10 to HvSnRK2 and 34 to HvSnRK3. The search was validated by applying it to Arabidopsis (Arabidopsis thaliana) and rice (Oryza sativa) genome data, identifying 50 SnRK genes in rice (four OsSnRK1, 11 OsSnRK2 and 35 OsSnRK3) and 39 in Arabidopsis (three AtSnRK1, 10 AtSnRK2 and 26 AtSnRK3). Specific motifs were identified in the encoded barley proteins, and multiple putative regulatory elements were found in the gene promoters, with light-regulated elements (LRE), ABA response elements (ABRE) and methyl jasmonate response elements (MeJa) the most common. RNA-seq analysis showed that many of the HVSnRK genes responded to ABA, some positively, some negatively and some with complex time-dependent responses.

(Continued on next page)
\end{abstract}

\footnotetext{
* Correspondence: liuchenghong@saas.sh.cn

${ }^{\dagger}$ Zhiwei Chen and Longhua Zhou are co-first authors.

${ }^{1}$ Biotechnology Research Institute, Shanghai Academy of Agricultural

Sciences, Shanghai 201106, China

${ }^{2}$ Shanghai Key Laboratory of Agricultural Genetics and Breeding, Shanghai

201106, China

Full list of author information is available at the end of the article
}

C C The Author(s). 2021 Open Access This article is licensed under a Creative Commons Attribution 4.0 International License, which permits use, sharing, adaptation, distribution and reproduction in any medium or format, as long as you give appropriate credit to the original author(s) and the source, provide a link to the Creative Commons licence, and indicate if changes were made. The images or other third party material in this article are included in the article's Creative Commons licence, unless indicated otherwise in a credit line to the material. If material is not included in the article's Creative Commons licence and your intended use is not permitted by statutory regulation or exceeds the permitted use, you will need to obtain permission directly from the copyright holder. To view a copy of this licence, visit http://creativecommons.org/licenses/by/4.0/ The Creative Commons Public Domain Dedication waiver (http://creativecommons.org/publicdomain/zero/1.0/) applies to the data made available in this article, unless otherwise stated in a credit line to the data. 
(Continued from previous page)

Conclusions: The barley HvSnRK gene family is large, comprising 50 members, subdivided into HvSnRK1 (6 members), HvSnRK2 (10 members) and HvSnRK3 (34 members), showing differential positive and negative responses to $A B A$.

Keywords: Barley, Hordeum vulgare, SnRK, Sucrose nonfermenting-1, Gene family, Abscisic acid, Metabolic regulation, Stress responses

\section{Background}

Sucrose nonfermenting-1 (SNF1)-related protein kinases (SnRKs) are related to SNF1 of fungi and AMP-activated protein kinase (AMPK) of mammals (see [1] for review). These protein kinases play important roles in regulating metabolism in all three systems, but in plants the SnRK family has expanded and diverged into three subfamilies, SnRK1 (structurally and functionally the most similar to SNF1 and AMPK), SnRK2 and SnRK3 [2]. SnRKs have been shown to be involved not only in the regulation of metabolism in plants but also in stress responses (see [2, 3] for reviews). Indeed, the burgeoning and divergence of this family of protein kinases in plants may have occurred to allow crosstalk between metabolic and stress signalling, enabling plants to use metabolic changes to adapt to stress conditions, for example by interchanging simple sugars and polysaccharides [3]. Therefore, the study of SnRKs in crops may lead to the development of strategies for breeding crop varieties that are more resilient under stress conditions. This is particularly important in the face of climate change and the prediction that extreme weather events are likely to become more frequent and more severe in the coming decades, with the potential for serious impacts on crop yield and quality.

A SnRK1 cDNA, initially called RKIN1, was first cloned from a rye (Secale cereale) endosperm cDNA library and shown to restore SNF1 function in yeast (Saccharomyces cerevisiae) snf1 mutants [4]. In fact, the gene usually referred to as $S n R K 1$ in plants actually encodes a catalytic subunit of a heterotrimeric protein. AMPK also comprises three subunits, a catalytic $\alpha$ subunit and accessory $\beta$ and $\gamma$ subunits, while the yeast protein comprises SNF1 (equivalent to AMPK $\alpha$ ), SNF4 (equivalent to AMPK $\gamma$ ) and one of three related proteins, SIP1, SIP2 and GAL83 (related to AMPK $\beta$ ) [2]. For this reason, the $S n R K 1$ gene is sometimes referred to as $A M P K \alpha$.

SnRK1 controls metabolism in part through the phosphorylation of enzymes such as 3-hydroxy-3-methylglutaryl coenzyme A reductase (HMG-CoA reductase) and sucrose phosphate synthase, leading to their inactivation. It also phosphorylates nitrate reductase, trehalosephosphate synthase, and 6-phosphofructo-2-kinase/fructose-2,6-bisphosphatase, but these enzymes also require the binding of a 14-3-3 protein for inactivation (see [2] for review). Another important metabolic enzyme, adenosine diphosphate (ADP)-glucose pyrophosphorylase, is regulated by SnRK1 through modulation of its redox state [5]. SnRK1 also acts through the regulation of gene activity, causing changes in gene expression in response to nutrient starvation [6] and herbivory [7]. SnRK1 has also been shown to channel carbon into the starch biosynthetic pathway in potato (Solanum tuberosum) tubers through modulation of sucrose synthase and ADP-glucose pyrophosphorylase gene expression [8, 9], and there is evidence that it plays a similar role in rice (Oryza sativa), sorghum (Sorghum bicolor) and maize (Zea mays) grain $[10,11]$ as well as sorghum and barley (Hordeum vulgare) pollen [11, 12]. Interestingly, both SNF1 and AMPK are required for storage carbohydrate synthesis in their respective systems, although the storage carbohydrate is different (glycogen instead of starch), the glucose donor is different (UDP-glucose instead of ADP-glucose) and the mechanisms of regulation are different [13, 14]. Paradoxically, SnRK1 is also required for the expression of $a$-Amy2 ( $\alpha$-amylase), a sugar-repressed gene that is involved in starch breakdown during germination [15].

The fact that SnRK1 phosphorylates and inactivates nitrate reductase provides a route through which SnRK1 can affect nitrogen metabolism. A second route is via asparagine synthetase gene expression, which has been shown to be regulated by SnRK1 in Arabidopsis (Arabidopsis thaliana) [6]. In wheat (Triticum aestivum), asparagine synthetase gene expression in the developing embryo increases in response to sulphur deficiency, and SnRK1 has been implicated in regulating this response $[16,17]$. Cereals contain a class of $S n R K 1$ genes that are expressed endosperm-specifically $[18,19]$ and these have been called $S n R K 1 b$ [1]. A third class that is closely related to $S n R K 1 b$ but is expressed in the embryo as well as the endosperm has recently been identified and called $S n R K 1 b^{*}$ [16]. It was this class that was suggested to be regulating asparagine synthetase gene expression in the wheat embryo [16].

There is also growing evidence that SnRK1 plays an important role in the defence against pathogens (see $[20,21]$ for reviews). Over-expression of SnRK1 in tomato (Solanum lycopersicum), for example, has been found to 
enhance viral resistance, while antisense suppression has the opposite effect [22]. SnRK1 overexpression has also been shown to confer broad-spectrum disease resistance in rice $[23,24]$, enhancing the defence response mediated by jasmonate [24]. In wheat, SnRK1 has been shown to interact with a protein, TaFROG, that enhances wheat's resistance to deoxynivalenol (DON), a mycotoxin produced by pathogenic Fusarium fungi [25]. DON treatment increases SnRK1 phosphorylation/activation and activity, while down-regulation of SnRK1 gene expression using virus-induced gene silencing (VIGS) increases the damaging effects of DON on wheat spikelets [25].

SnRK1 will phosphorylate peptides containing a serine residue (much preferred to threonine) with hydrophobic residues at positions -5 and +4 with respect to the serine, and a basic residue at position -3 or, less favourably, $-4[1,26]$. However, plant extracts generally contain two additional activity peaks that will phosphorylate this target site, as well as the one accounted for by SnRK1 [26-29], and these came to be called SnRK2 and SnRK3 [1]. It was soon apparent that a SnRK2 cDNA had already been cloned from wheat and named $p k A B A 1$, the name being assigned because $p k A B A 1$ mediates ABA-induced changes in gene expression in response to cold, dehydration and osmotic stress [30, 31]. A very similar $S n R K 2$ gene, SAPK2, confers ABA sensitivity and drought tolerance in rice [32]. The SnRK2 gene family is unique to plants and has expanded and diversified to comprise, for example, 10 members in Arabidopsis [2]. SnRK2s are much smaller than SnRK1, with molecular weights typically around $40 \mathrm{kDa}$ compared with $58 \mathrm{kDa}$ for SnRK1, and do not complement the snf1 mutation of yeast [1]. Indeed, SnRK2s are only large enough to include a protein kinase domain and a short, truncated, acidic C-terminal domain. They are associated with a variety of abiotic stress responses [3, 33-36], and are integral to the abscisic acid (ABA) response pathway [34, 37-39], becoming active in response to $A B A$ and phosphorylating transcription factors of the ABAresponse-element-binding protein class (AREBPs). These transcription factors have been shown to be substrates for SnRK1 and SnRK3 as well [40], making them potential convergence points for multiple signalling pathways.

Halford and Hardie [1] divided SnRK2s into two subclasses, SnRK2a and SnRK2b, based on whether their acidic C-terminal domain contained an aspartic acid- or glutamic acid-rich patch. Subsequently, Kobayashi et al. [33] identified three subclasses, I, II and III, with subclass I equivalent to SnRK2b (glutamic acid-rich Cterminal patch) and subclasses II and III representing subdivisions of SnRK2a (aspartic acid-rich patch). These subclasses have been shown to respond differently to ABA, with subclass I not activated by ABA, subclass II not activated or activated very weakly by $A B A$, and subclass III strongly activated by ABA [41-44]. ABA is, of course, strongly associated with stress responses (see [45] for review), but it is also a key player in driving grain maturation and, in particular, the switch from the grain filling to maturation phases of grain development [46]. ABA has a very different effect on SnRK1 than SnRK2, promoting SnRK1 degradation in wheat roots, for example, while promoting SnRK2 phosphorylation/ activation [47]. It has been suggested that the ABAdriven degradation of SnRK1 together with the activation of SnRK2 could be the trigger that pushes developing grain into the maturation phase [48].

The first SnRK3 gene to be characterized was also from wheat, and was initially named wpk4 $[49,50]$. The $S n R K 3$ gene family is even larger than the $S n R K 2$ family, with the Arabidopsis genome containing 25 SnRK3 genes [2]. Unlike SnRK1 and SnRK2, SnRK3 is believed to be calcium-dependent, because it interacts with a calcium-binding protein, calcineurin B-like protein (CBL) [36, 51-53]. This has led to SnRK3s being more popularly known as CIPKs (CBL-interacting protein kinases). One of the most extensively characterized SnRK3/CIPKs is SOS2 (salt overly sensitive 2), which is involved in the response to salt stress [51, 54-57]. Sodium ions are just one of many species of ions that plants take up from the soil, of course, and, while many are important nutrients, some can be toxic at high concentrations. SnRK3s/CIPKs are now considered to be involved generally in enabling plants to adapt to changing ionic conditions. Their roles have recently been reviewed in depth by Tang et al. [58] and Ma et al. [59].

SnRKs represent one of the largest families within the plant kinome, and their positioning at the interface between metabolic, stress and ABA signalling has made them the focus of studies in many plant species. As whole genome data have become available for many species, along with powerful bioinformatics tools, the identification of entire $S n R K$ gene familes at the genome level has become possible, for example in Arabidopsis, Brachypodium distachyon, Chinese cabbage (Brassica rapa), soybean (Glycine max), and oilseed rape (Brassica napus) [36, 60-63]. However, the role of ABA in driving developmental changes in cereal seed development, the differential effects of ABA on the different SnRK families, and the role of SnRKs in regulating processes that affect grain composition, such as starch accumulation and asparagine biosynthesis, make the study of SnRKs in cereals particularly important. Barley was the first plant species in which a characterization of the SnRK1 gene family was begun, with three different members of the family, called BKIN2, BKIN9 and BKIN12 at that time, shown to have different gene structures and to be differentially-expressed, with BKIN12, subsequently assigned to the $S n R K 1 b$ class, expressed specifically in 
the endosperm tissue of the grain $[18,19]$. Here we report the analysis of the entire $S n R K$ gene family of barley by using the barley genome data from Ensembl. It is the first comprehensive analysis of the $S n R K$ gene family of a commercial cereal species.

\section{Results \\ Genome-wide identification of the SnRK gene family members in barley}

In total, $50 \mathrm{HvSnRKs}$ were found to be encoded in the barley genome (Table 1), of which six were classed as SnRK1s by Pfams analysis and called HvSnRK1.1 HvSnRK1.6. Each of these contained a kinase associated domain KA1 (Pfams reference PF02149), and all except one, HvSnRK1.2, also contained an ubiquitin-associated domain (UBA) (PF00627). Thirty-four proteins were assigned to the SnRK3/CIPK group based on the presence of a NAF domain (PF03822), a 24 amino acid domain required for binding to CBLs [64]. The remaining 10 proteins were assigned to the SnRK2 group. The proteins comprised between 232 and 797 amino acid residues and had molecular weights ranging from 25.9 to $89.9 \mathrm{kDa}$ (see Table 1). The smallest of these, one of the SnRK3s/CIPKs, is not large enough to include a complete kinase domain and is unlikely to be functional.

Within the SnRK1 group, HvSnRK1.3, 1.4, 1.5 and 1.6 were most similar to the SnRK1b-type protein annotated previously as BKIN12, while SnRK1.1 and SnRK1.2 were most similar to the SnRK1a-type protein, BKIN2 [18, 19]. HvSnRK1.3 and HvSnRK1.4 were assigned to SnRK1b, while SnRK1.5 and HvSnRK1.6 were assigned to SnRK1b*.

The isoelectric point of the HvSnRK1s ranged from 6.68 to 9.45 , the HvSnRK2s from 4.80 to 8.55 , and the HvSnRK3s from 5.37 to 9.51 (Table 1). The subcellular localization of HvSnRK1.2, HvSnRK3.4 and HvSnRK3.27 was predicted to be in the chloroplast (Table 1), while HvSnRK1.4, HvSnRK2.6, HvSnRK3.5, HvSnRK3.13, HvSnRK3.17, HvSnRK3.19, HvSnRK3.20, HvSnRK3.21, HvSnRK3.22 and HvSnRK3.33 were predicted to localize to the mitochondrion, and HvSnRK3.29 to the secretory pathway. The others are likely to be cytosolic. The fact that SnRK1 is targeted to different cellular locations has led to the hypothesis that it mediates energy signaling between different organelles [65].

To validate our screen and to compare and contrast the SnRK families across species, we also identified SnRKs from rice and Arabidopsis. The rice family comprised a total of 50 OsSnRKs, made up of four OsSnRK1s, eleven OsSnRK2s and 35 OsSnRK3s, while the Arabidopsis family comprised 39 AtSnRKs, including three AtSnRK1s, 10 AtSnRK2s and 26 AtSnRK3s (Additional file 1). The Arabidopsis family included one additional SnRK3 compared with those identified by Halford and Hey [2].

\section{Phylogenetic analyses}

A rooted phylogenetic analysis was conducted for all the SnRKs identified from barley, rice and Arabidopsis. The phylogenetic tree that was generated (Fig. 1) confirmed the three major groups of SnRK1, SnRK2 and SnRK3, and the assignation of each barley SnRK to the groups confirmed the Pfams analysis, although one of the rice genes that had been classified as encoding a SnRK2 by Pfams appeared in the SnRK3 cluster in the phylogenetic analysis and was named OsSnRK3.35. Note that SnRK1 is more closely related to SNF1 of yeast and AMPK of mammals than it is to SnRK2 and SnRK3 [1]. While SnRK2 and SnRK3 are plant-specific and presumably diverged from SnRK1 after the separation of animals, plants and fungi, they must have evolved rapidly as they took on different functions.

A second phylogenetic tree of the barley HvSnRKs alone was produced using different software. The phylogenetic tree that was generated (Fig. 2a) confirmed the clustering into the HvSnRK1, HvSnRK2 and HvSnRK3 families. As before, the SnRK1 family could be further divided into subclasses, corresponding to SnRK1a (SnRK1.1 and 1.2), SnRK1b (SnRK1.3 and 1.4) and SnRK1b* (SnRK1.5 and 1.6). Similarly, the SnRK2 subgroup was divided into two subclasses, corresponding to SnRK2a and SnRK2b as defined by Halford and Hardie [1] and SnRK2 subclass II/III and SnRK2 subclass I as defined by Kobayashi et al. [33] (subclasses II/III did not separate clearly in this analysis).

Gene structure, conserved motifs and promoter analysis There were 11 exons in all the $H v S n R K 1$ genes except for $H \nu S n R K 1.5$, and 9 exons in all of the $H \nu S n R K 2$ genes except for $H v S n R K 2.7$. In contrast, the exon/intron structure of the $H v S n R K 3 s$ varied greatly, ranging from 1 exon to 16 (Fig. 2b), indicating that the genes in the $H \nu S n R K 1$ and $H \nu S n R K 2$ subfamilies are more conserved in structure than those in the $H v S n R K 3$ subfamily.

The motif analysis of the HvSnRK proteins (Fig. 2c) showed that all the HvSnRK1s had seven motifs, 1, 2, 3, 4, 5, 6 and 10, apart from HvSnRK1.5, which lacked the first three motifs. All of the HvSnRK2s had motifs 1, 2, 3, 4 and 6; in other words they lacked motifs 5 and 10 of the HvSnRK1s. They are, of course, readily distinguishable from the SnRK1s on the basis of size, being much smaller (around $40 \mathrm{kDa}$ compared with around $58 \mathrm{kDa}$ ). That is not true of the SnRK3s, which vary considerably in size. However, the SnRK3s were characterized by the presence of the first six motifs identified in the SnRK1s but also by three additional motifs, 7, 8 and 9, that were not present in the SnRK1s, and the lack of motif 10. The exceptions were HvSnRK3.9, which 
Table 1 Characteristics of HvSnRKs from barley

\begin{tabular}{|c|c|c|c|c|c|c|}
\hline Gene name & Gene ID & CDS length (bp) & $\begin{array}{l}\text { Peptide length } \\
\text { (aa) }\end{array}$ & $\mathrm{pl}$ & MW (KDa) & Localization \\
\hline HvSnRK1.1 & HORVU1Hr1G081310 & 1563 & 520 & 8.7 & 59.04 & - \\
\hline HvSnRK1.2 & HORVU3Hr1G069190 & 1716 & 571 & 9.45 & 65.01 & Chloroplast \\
\hline HvSnRK1.3 & HORVU3Hr1G107970 & 1647 & 548 & 6.68 & 62.19 & - \\
\hline HvSnRK1.4 & HORVU3Hr1G107990 & 1659 & 552 & 7.65 & 63.28 & Mitochondrion \\
\hline HvSnRK1.5 & HORVU3Hr1G108000 & 1041 & 346 & 7.06 & 39.48 & - \\
\hline HvSnRK1.6 & HORVU4Hr1G056610 & 1545 & 514 & 8.58 & 58.81 & - \\
\hline HvSnRK2.1 & HORVU1Hr1G055340 & 1026 & 341 & 5.99 & 38.53 & - \\
\hline HvSnRK2.2 & HORVU2Hr1G029900 & 1389 & 462 & 6.52 & 51.57 & - \\
\hline HvSnRK2.3 & HORVU2Hr1G075470 & 1074 & 357 & 5.54 & 40.90 & - \\
\hline HvSnRK2.4 & HORVU2Hr1G110230 & 1035 & 344 & 5.8 & 39.11 & - \\
\hline HvSnRK2.5 & HORVU2Hr1G125950 & 1125 & 374 & 8.55 & 41.85 & - \\
\hline HvSnRK2.6 & HORVU3Hr1G082690 & 1146 & 382 & 7.72 & 44.21 & Mitochondrion \\
\hline HvSnRK2.7 & HORVU4Hr1G013540 & 1086 & 361 & 4.8 & 40.65 & - \\
\hline HvSnRK2.8 & HORVU5Hr1G018340 & 1116 & 371 & 4.99 & 41.33 & - \\
\hline HvSnRK2.9 & HORVU5Hr1G097630 & 1101 & 366 & 4.86 & 41.53 & - \\
\hline HvSnRK2.10 & HORVUOHr1G011570 & 1074 & 357 & 4.94 & 40.15 & - \\
\hline HvSnRK3.1 & HORVU1Hr1G017240 & 1479 & 492 & 8.49 & 54.96 & - \\
\hline HvSnRK3.2 & HORVU1Hr1G017380 & 1488 & 495 & 8.44 & 54.91 & - \\
\hline HvSnRK3.3 & HORVU1Hr1G070100 & 1491 & 497 & 9.43 & 56.43 & - \\
\hline HvSnRK3.4 & HORVU1Hr1G076910 & 1533 & 510 & 7.24 & 57.03 & Chloroplast \\
\hline HvSnRK3.5 & HORVU2Hr1G016750 & 1347 & 448 & 8.01 & 50.74 & Mitochondrion \\
\hline HvSnRK3.6 & HORVU2Hr1G018260 & 1353 & 450 & 9.07 & 50.83 & - \\
\hline HvSnRK3.7 & HORVU2Hr1G018340 & 1512 & 504 & 6.86 & 54.48 & - \\
\hline HvSnRK3.8 & HORVU2Hr1G027080 & 1356 & 451 & 7.95 & 51.13 & - \\
\hline HvSnRK3.9 & HORVU2Hr1G031190 & 699 & 232 & 5.37 & 25.90 & - \\
\hline HvSnRK3.10 & HORVU2Hr1G031200 & 825 & 274 & 5.67 & 30.67 & - \\
\hline HvSnRK3.11 & HORVU2Hr1G060350 & 1386 & 461 & 9.15 & 51.77 & - \\
\hline HvSnRK3.12 & HORVU2Hr1G117610 & 1377 & 458 & 8.9 & 50.78 & - \\
\hline HvSnRK3.13 & HORVU3Hr1G025810 & 1536 & 511 & 8.4 & 56.39 & Mitochondrion \\
\hline HvSnRK3.14 & HORVU3Hr1G029350 & 1692 & 563 & 8.88 & 63.16 & - \\
\hline HvSnRK3.15 & HORVU3Hr1G073100 & 1731 & 576 & 8.91 & 63.97 & - \\
\hline HvSnRK3.16 & HORVU3Hr1G073110 & 1437 & 478 & 8.88 & 53.12 & - \\
\hline HvSnRK3.17 & HORVU3Hr1G081420 & 1530 & 509 & 8.85 & 57.65 & Mitochondrion \\
\hline HvSnRK3.18 & HORVU4Hr1G021090 & 1329 & 442 & 9.04 & 48.16 & - \\
\hline HvSnRK3.19 & HORVU4Hr1G022630 & 1335 & 444 & 9.16 & 50.38 & Mitochondrion \\
\hline HvSnRK3.20 & HORVU4Hr1G026300 & 1323 & 440 & 7.18 & 50.41 & Mitochondrion \\
\hline HvSnRK3.21 & HORVU4Hr1G052200 & 1350 & 449 & 8.27 & 50.98 & Mitochondrion \\
\hline HvSnRK3.22 & HORVU4Hr1G083080 & 1338 & 445 & 7.67 & 49.91 & Mitochondrion \\
\hline HvSnRK3.23 & HORVU5Hr1G014200 & 1302 & 433 & 9.51 & 47.50 & - \\
\hline HvSnRK3.24 & HORVU5Hr1G046830 & 1341 & 447 & 9.13 & 50.43 & - \\
\hline HvSnRK3.25 & HORVU5Hr1G046880 & 1323 & 440 & 9.25 & 49.61 & - \\
\hline HvSnRK3.26 & HORVU5Hr1G065350 & 1341 & 446 & 9.17 & 47.92 & - \\
\hline HvSnRK3.27 & HORVU5Hr1G065370 & 1515 & 504 & 8.81 & 55.59 & Chloroplast \\
\hline
\end{tabular}


Table 1 Characteristics of HvSnRKs from barley (Continued)

\begin{tabular}{lllllll}
\hline Gene name & Gene ID & CDS length (bp) & $\begin{array}{l}\text { Peptide length } \\
\text { (aa) }\end{array}$ & pl & MW (KDa) & Localization \\
\hline HvSnRK3.28 & HORVU5Hr1G093660 & 1296 & 431 & 8.82 & 47.16 & - \\
HvSnRK3.29 & HORVU6Hr1G025940 & 2394 & 797 & 6.36 & 89.93 & Secretory pathway \\
HvSnRK3.30 & HORVU6Hr1G030150 & 1329 & 442 & 7.91 & 49.58 & - \\
HvSnRK3.31 & HORVU6Hr1G054210 & 1314 & 438 & 8.61 & 48.28 & - \\
HvSnRK3.32 & HORVU7Hr1G089510 & 1461 & 486 & 8.74 & 54.14 & - \\
HvSnRK3.33 & HORVU7Hr1G090260 & 1518 & 505 & 9.11 & 56.21 & Mitochondrion \\
HvSnRK3.34 & HORVU0Hr1G015380 & 1398 & 465 & 9.03 & 52.86 & - \\
\hline
\end{tabular}

"_" represents any other location. The localization, pl and MW are just predictions

lacked the first five motifs, HvSnRK3.10, which lacked the first four motifs and motif 7, HvSnRK3.27, which lacked the first motif, and HvSnRK3.27, which had additional motifs 1, 2 and 9 before the shared nine motifs. Interestingly, motif 9 was also present in SnRK2.1, but motifs 7 and 8 were not. The presence/absence of these motifs could allow for the simple allocation of SnRKs from other species into the correct subgroup.

Considering that HvSnRKs play important roles in many biological processes, the promoters of the genes were analyzed to identify potential regulatory elements that could give clues as to how the genes are regulated and the different stimuli they respond to. Of the $50 \mathrm{HvSnRK}$ genes, two (HvSnRK3.9 and HvSnRK3.10) lacked data for the promoter regions, but the analysis identified 18 different types of ciselement in the promoter regions of 47 of the other 48 $H \nu S n R K$ genes (Fig. 3, Additional file 2). Apart from the one promoter (that of $H v S n R K 3.31$ ) lacking any of these elements, each promoter contained between 2 and 9 of the different types of cis-element, with the promoters of $H \nu S n R K 1.6$ and HvSnRK3.11 containing the most. The most frequently present types of element were light-responsive elements (LRE), abscisic acid (ABA)-responsive elements (ABRE), and methyl jasmonate (MeJA)-responsive elements, which appeared in 46, 39 and 36 of the promoters, respectively. Excepting $H v S n R K 3.9, H \nu S n R K 3.10$ and $H v S n R K 3.31$, all of the genes except $H v S n R K 2.6$ have the LRE. The ABRE is present in the promoters of all the $H \nu S n R K 1 s$, all the $H \nu S n R K 2 s$ apart from $H \nu S n R K 2.8$ and $H \nu S n R K 2.10$, and all the HvSnRK3s apart from $H v S n R K 3.2, H \nu S n R K 3.20$, HvSnRK3.23, HvSnRK3.26, HvSnRK3.27 and HvSnRK3.33. The MeJA-responsive element is present in $H v S n R K 1.2$, $H \nu \operatorname{SnRK1.3}$ and HvSnRK1.4, as well as all the HvSnRK2s

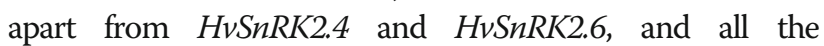
$H \nu$ SnRK3s apart from HvSnRK3.1, HvSnRK3.6, HvSnRK3.16,

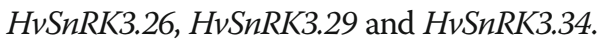

\section{Chromosomal location, gene duplication and gene synteny analysis}

Chromosomal location analysis showed the $50 \mathrm{HvSnRK}$ genes to be distributed across all seven barley chromosomes (Fig. 4). Four of the six $H v S n R K 1$ genes were located to Chromosome 3, with HvSnRK1.1 on Chromosome 1 and HvSnRK1.6 on Chromosome 4. $H v S n R K 2$ genes were distributed on Chromosomes 1-5, with HvSnRK2.1 on Chromosome 1, HvSnRK2.2, 2.3, 2.4 and 2.5 on Chromosome 2, SnRK2.6 on Chromosome 3, SnK2.7 on Chromosome 4, and $H v \operatorname{SnRK2.8}$ and 2.9 on Chromosome 5. SnRK2.10 was unclassified. HvSnRK3 genes were distributed on all of the chromosomes, with most (8) on Chromosome 2.

Gene duplication analysis of the $H \nu \operatorname{SnRK}$ genes showed that there were two segmental duplication events between different chromosomes and two tandem duplication events (Fig. 4), while there was only one interval gene in the cluster of $H \nu S n R K 1.3, H \nu S n R K 1.4$ and HvSnRK1.5. The KaKs calculation showed the Ka/ Ks values of all the duplication pairs to be less than 1 , especially the segmental duplication pairs (Table 2). The results also suggested that the $H v \operatorname{SnRK}$ genes related to those duplications were conserved, with purifying selection (the selective removal of alleles that are deleterious).

Gene synteny analyses were performed for the barley $H v S n R K$ gene family and the corresponding gene families of Arabidopsis and rice. The results showed that 38 of the $50 \mathrm{HvSnRKs}$ had homologues in Arabidopsis and 39 in rice (Fig. 5, Additional file 3). The fact that 11 HvSnRKs did not have homologues in either Arabidopsis or rice suggested that the differentiation and specificity of $H \nu S n R K s$ has evolved further in barley. In addition, one $H v S n R K$ had several homologues in Arabidopsis, while several $H \nu S n R K s$ were homologous to a single AtSnRK. In contrast, most HvSnRKs had only one homologous gene in rice.

\section{Gene expression analysis of HvSnRKs in response to ABA treatment}

Barley seedlings of variety Morex were cultured in nutrient solution and treated with either $50 \mu \mathrm{M}$ ABA dissolved in ethanol or ethanol alone (the control). Roots were harvested at $1 \mathrm{~h}, 3 \mathrm{~h}, 6 \mathrm{~h}$ and $24 \mathrm{~h}$ after treatment, 


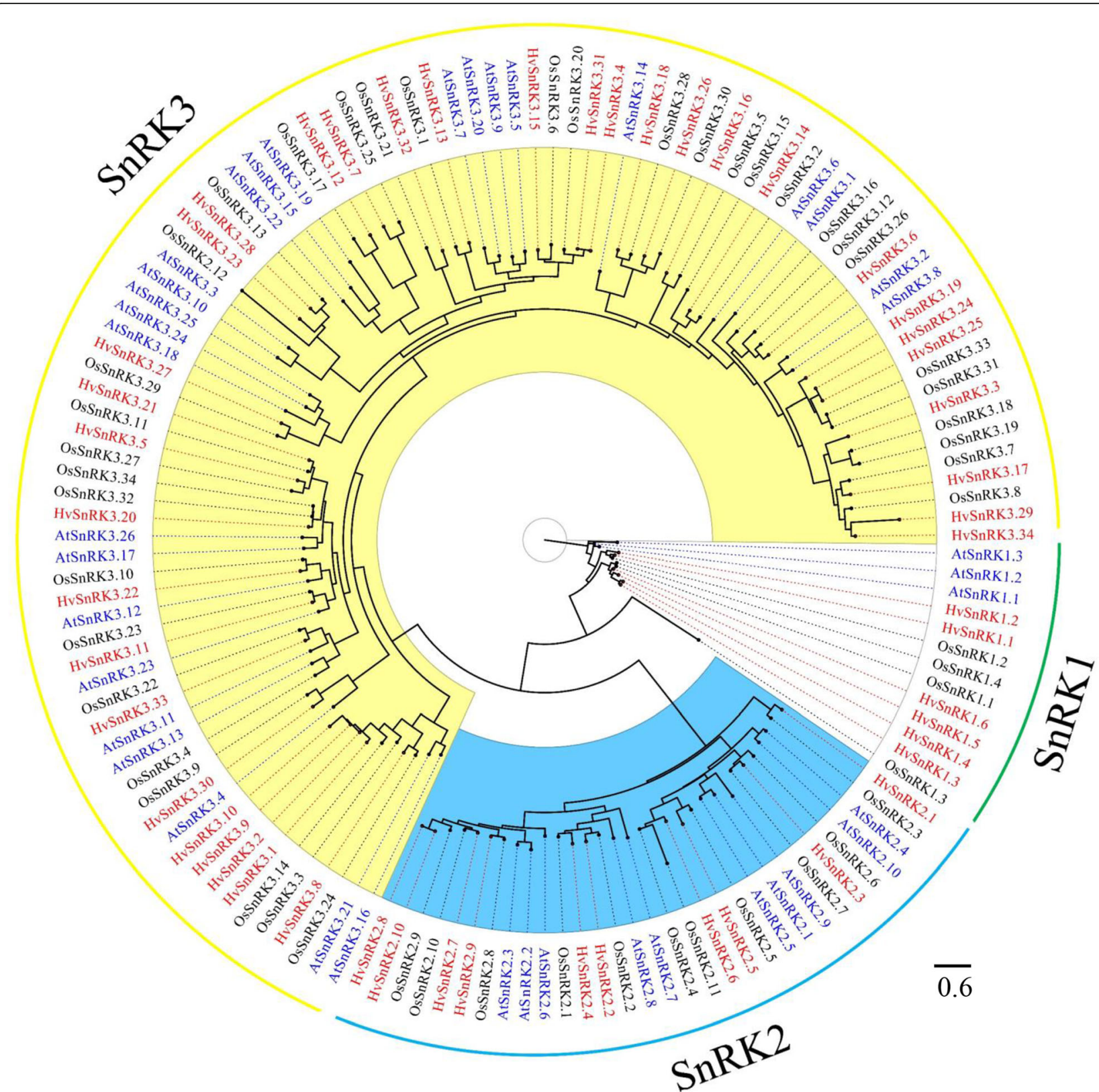

Fig. 1 Phylogenetic tree of SnRK proteins from barley, rice and Arabidopsis. The Maximum-Likelihood tree (JTT $+I+G+F)$ was constructed using RAxML with conserved protein kinase domain regions of 139 SnRKs. Different colour fonts represent SnRKs from barley (red), rice (black) and Arabidopsis (blue). Different colour sectors represent SnRKs from SnRK1 subgroup (white), SnRK2 (blue) and SnRK3 (yellow)

with three biological replicates per treatment/time. RNA-seq analysis was performed and reads aligned to the Ensembl Plants database for barley. Gene expression was calculated as the number of reads that mapped to each gene per kilobase of transcript, per million mapped reads (RPKM). The RNA-seq data have been deposited with the National Center for Biotechnology Information: BioProject ID PRJNA661163.

In total, 41 of the $50 \mathrm{HvSnRK}$ genes were found to be expressed in the roots, and 30 were affected significantly $(p<0.05)$ by the ABA treatment (Fig. 6, Additional file 4). Only one gene, $H v S n R K 3.13$, was up-regulated by the ABA treatment at all the time-points, while four genes, HvSnRK2.4, HvSnRK3.1, HvSnRK3.2 and HvSnRK3.9, were up-regulated at $3 \mathrm{~h}, 6 \mathrm{~h}$ and $24 \mathrm{~h}$. One gene,

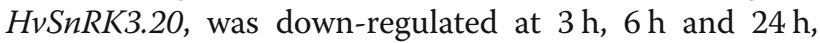
while five genes $(H \nu S n R K 3.4, H v S n R K 3.11, H v S n R K 3.26$, $H v S n R K 3.27$ and $H v S n R K 3.28)$ were up-regulated at $3 \mathrm{~h}$ and $6 \mathrm{~h}$ of treatment and two genes $(H \nu S n R K 3.5$ and $H \nu \operatorname{SnRK3.8)}$ were up-regulated at $6 \mathrm{~h}$ and $24 \mathrm{~h}$ of 

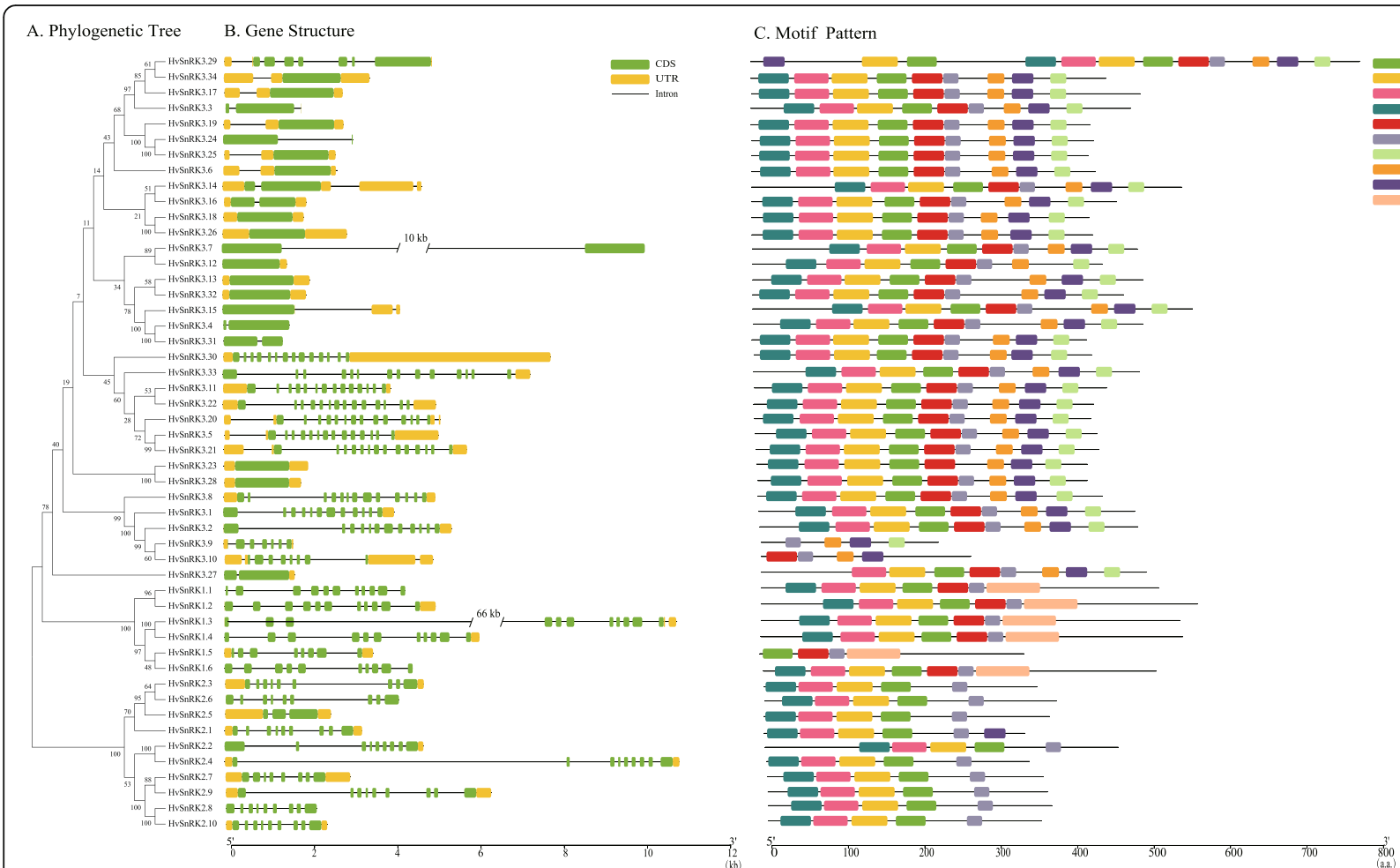

Fig. 2 Phylogenetic relationships, gene structure and architecture of conserved protein motifs of the SnRK gene family from barley. a. Phylogenetic tree of $50 \mathrm{HvSnRKs}$ constructed using the Neighbor-Joining (NJ) method using MEGA 7.0 with full length amino acids sequences of $50 \mathrm{HvSnRKs}$ proteins. b. Gene structures of $50 \mathrm{HvSnRK}$ genes. Green boxes represent exons, yellow boxes represent 5' or 3' untranslated regions (UTR), and black lines represent introns. The length of nucleotide sequences of exons/introns/UTRs can be estimated by the scale at the bottom. c. The motif compositions of $50 \mathrm{HvSnRK}$ proteins (Figure S2). The motifs were identified using the MEME program. Boxes of different colors represent motif 1 to 10, respectively. The length of amino acid sequences can be estimated by the scale at the bottom

treatment. $H v S n R K 3.19$ was up-regulated at $1 \mathrm{~h}$ after ABA treatment but not at the other timepoints, while $H \nu S n R K 2.6, H \nu \operatorname{SnRK2.7}$ and $H \nu \operatorname{SnRK3.32}$ were upregulated at $3 \mathrm{~h}$ after ABA treatment. $H v S n R K 3.23$ was down-regulated at $6 \mathrm{~h}$ after ABA treatment, but not the other timepoints, while HvSnRK3.32 was downregulated at $3 \mathrm{~h}$ after $\mathrm{ABA}$ treatment. $H \nu S n R K 3.31$ and $H v S n R K 3.34$ were up-regulated at $6 \mathrm{~h}$ after $\mathrm{ABA}$ treatment, while $H \nu S n R K 3.30$ down-regulated. Four genes $(H \nu S n R K 3.12, H \nu S n R K 3.21, H \nu S n R K 3.22$ and $H \nu \operatorname{SnRK3.28}$ were up-regulated only at $24 \mathrm{~h}$ after $\mathrm{ABA}$ treatment. Three further genes $(H \nu S n R K 2.1, H \nu S n R K 2.8$ and $H \nu S n R K 3.24$ ) showed more complicated responses, with $H \nu S n R K 2.1$ down-regulated at $1 \mathrm{~h}$ after ABA treatment, then up-regulated at $3 \mathrm{~h}, 6 \mathrm{~h}$ and $24 \mathrm{~h}, H \nu \operatorname{SnRK} 2.8$ up-regulated at $1 \mathrm{~h}$ after ABA treatment, then downregulated at $6 \mathrm{~h}$, and $H v S n R K 3.24$ down-regulated at $1 \mathrm{~h}$ after ABA treatment, then up-regulated at $3 \mathrm{~h}$ and $6 \mathrm{~h}$. In all, half of the HvSnRK2 genes and more than two thirds of the $H \nu S n R K 3$ genes responded to ABA, showing a complex picture of differential regulation. This is consistent with the $H v S n R K 2$ and $H \nu S n R K 3$ genes playing important roles in ABA responses $[58,59]$.
In contrast, of the $4 H \nu \operatorname{SnRK1}$ genes that were expressed, none showed a significant change in expression in response to ABA. ABA has been shown to influence SnRK1 in wheat roots but at the post-translational rather than transcriptional level [47].

\section{Discussion}

SnRKs play important roles in linking stress and $A B A$ signalling with metabolic signalling in plants. Barley is the fourth most important cereal crop in the world in terms of production, and its widespread cultivation can be attributed in part to its good adaptation to different environments. This makes the elucidation of the SnRK gene family in this species particularly important. In this study, a total of 50 barley $H \nu S n R K$ genes were identified, providing a basis for studying their roles individually, or as subfamilies or as an entire gene family.

BLAST searches or HMM searches or both are usually used for identifying gene homologues and families of homologues, and both types of search were adopted for this study. The methodology was validated by applying it to rice and Arabidopsis and showing that it identified all of the $S n R K$ genes in those species. Halford and Hardie 


\begin{tabular}{|c|c|c|}
\hline$H v \operatorname{SnRK1.1}$ & $-0-a-2-0-0$ & \\
\hline$H v \operatorname{SnRK1.2}$ & $0-0-1000-00-0-00-0-0-0,0-0-0-0-$ & Light \\
\hline$H v S n R K 1.3$ & $0-0-000-00-1$ & GA \\
\hline$H v \operatorname{SnRK1.4}$ & $0,00000-000-00-0,-00-$ & SA \\
\hline$H v \operatorname{SnRK1.5}$ & 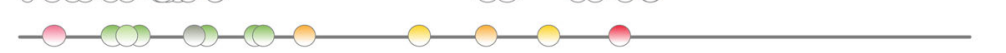 & $\mathrm{ABA}$ \\
\hline$H v S n R K 1.6$ & 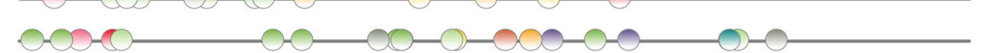 & Meristem specific \\
\hline$H v S n R K 2.1$ & $-\cos 2000-0$ & $\square$ MeJA \\
\hline$H v \operatorname{SnRK} 2.2$ & 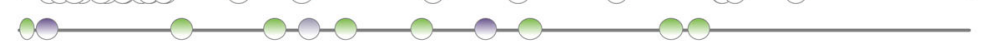 & $\begin{array}{l}\text { Anaerobic induction } \\
\text { Auxin }\end{array}$ \\
\hline$H v \operatorname{SnRK} 2.3$ & $-a-\infty-0-0-0-\infty-\infty-0$ & Auxin \\
\hline$H v \operatorname{SnRK2.4}$ & $0-0-0-\cos -1-2=$ & Drought \\
\hline$H v \operatorname{SnRK} 2.5$ & $7+2-0-200-1$ & $\begin{array}{l}\text { Seed specific } \\
\text { Low temperature }\end{array}$ \\
\hline$H \nu \operatorname{SnRK2.6}$ & 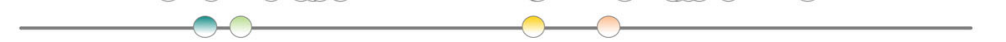 & $\begin{array}{l}\text { Low temperature } \\
\text { Stress }\end{array}$ \\
\hline$H v S n R K 2.7$ & $-2-\cos -0-0-2-$ & $\begin{array}{l}\text { Stress } \\
\text { Endosperm specific }\end{array}$ \\
\hline$H v \operatorname{SnRK} 2.8$ & $-\infty, 00-0$ & Wound \\
\hline$H \nu \operatorname{SnRK2.9}$ & $-0-\infty-0-0-0,-\infty 0-0$ & \\
\hline$H v \operatorname{SnRK2.10}$ & $-0-\infty$ & \\
\hline $\begin{array}{l}H v \operatorname{SnRK3.1} \\
H v \operatorname{Sn} R K 3.2\end{array}$ & $-0-\infty-0-0-0-0-a-0-a-a$ & \\
\hline & 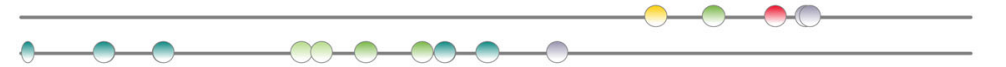 & \\
\hline$H v \operatorname{SnRK3.4}$ & 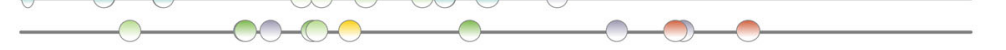 & \\
\hline$H v S n R K 3.5$ & 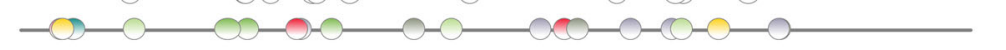 & \\
\hline$H v \operatorname{SnRK3.6}$ & $-C_{-0}-0$ & \\
\hline$H v S n R K 3.7$ & $0-0-0-0-\infty-00-0-\infty-0-0-\infty-2)$ & \\
\hline$H v \operatorname{SnRK3.8}$ & $-0-C-C-60-0-00-00-00000$ & \\
\hline$H v \operatorname{SnRK3.11}$ & $-0-0-0-0-0-0-0-0$ & \\
\hline$H v \operatorname{SnRK3.12}$ & $-0-\infty 00-0-0,-00-0-0$ & \\
\hline$H v S n R K 3.13$ & $-0-1-000-0-0,00-1$ & \\
\hline$H v S n R K 3.14$ & $-0-0-0-0-0-0-0-0$ & \\
\hline$H v \operatorname{SnRK3.15}$ & $-0-0-0-0-0-0-0-0-0$ & \\
\hline$H v S n R K 3.16$ & $0-0-0-2-2$ & \\
\hline HvSnRK3.17 & 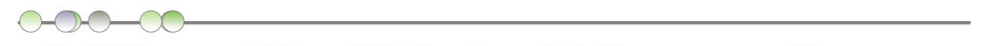 & \\
\hline$H v \operatorname{SnRK3.18}$ & 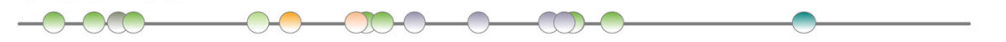 & \\
\hline HvSnRK3.19 & 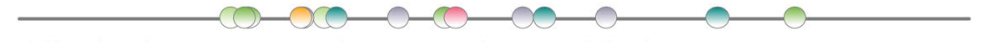 & \\
\hline$H v \operatorname{SnRK3.20}$ & $\mathrm{CO}-\mathrm{O}-\mathrm{O}-\mathrm{C}-\mathrm{C}-\mathrm{C}-\mathrm{CO}-\mathrm{O}$ & \\
\hline$H v S n R K 3.21$ & 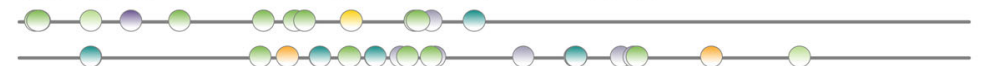 & \\
\hline $\begin{array}{l}H v S n R K 3.22 \\
H v S n R K 3.23\end{array}$ & & \\
\hline$H v S n R K 3.24$ & $-\infty-\infty-a-\infty$ & \\
\hline$H v \operatorname{SnRK} 3.25$ & $-0-1-0-0-0-0-020-1-0$ & \\
\hline$H v S n R K 3.26$ & -0 & \\
\hline$H v S n R K 3.27$ & $0-0-1-0-\infty-\infty-O-\infty$ & \\
\hline$H v S n R K 3.28$ & $+\infty-2-O C-O$ & \\
\hline $\begin{array}{l}H v \operatorname{SnRK3.29} \\
\text { HvSnRK3.30 }\end{array}$ & 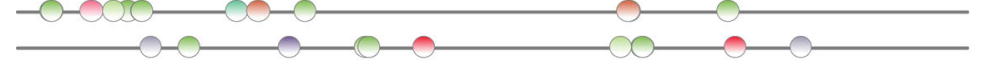 & \\
\hline $\begin{array}{l}H v S n R K 3.30 \\
H v S n R K 3.32\end{array}$ & 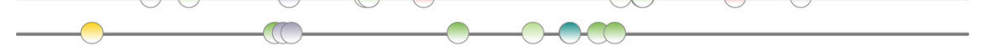 & \\
\hline$H v \operatorname{SnRK3.33}$ & $-0-0$ & \\
\hline \multirow[t]{3}{*}{$H v S n R K 3.34$} & $-\infty-\infty-0-0-\infty-0-0-0$ & \\
\hline & & \\
\hline & 1500 & \\
\hline
\end{tabular}

separated the SnRKs into three subgroups: SnRK1, SnRK2 and SnRK3, with the molecular weight of SnRK1 around $58 \mathrm{kDa}$ and SnRK2 around $40 \mathrm{kDa}$, with more variability for SnRK3 [1]. The HvSnRKs separated clearly into these three subgroups, and clustered with the corresponding subgroups of rice and Arabidopsis in phylogenetic analyses, indicating that the three SnRK subgroups were established before the divergence of dicot and monocot plants. This was also inferred by Wang et al. [60] in the identification of BdSnRKs in Brachypodium distachyon. Motif analysis of the encoded proteins also distinguished the three subfamilies, and the 


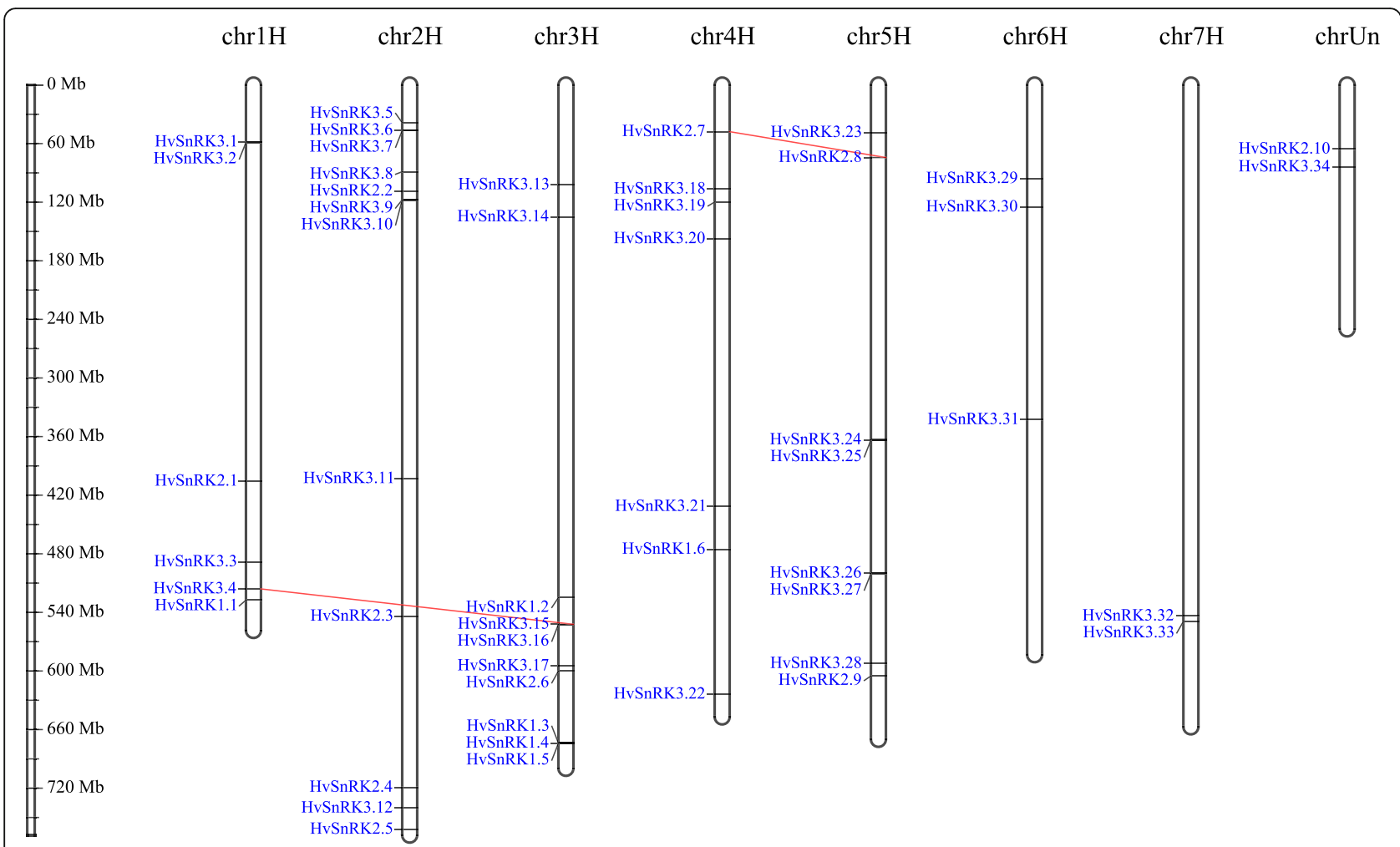

Fig. 4 Chromosomal locations of HvSnRK genes. Positions linked by red lines represent segmental duplications within HvSnRK genes, while yellow rectangles represent tandem duplications with related HvSnRK genes. The length of chromosomes can be estimated using the scale on the left. HvSnRK2.10 and HvSnRK3.34 were unclassified

presence/absence of different motifs could be used to assign SnRKs to the correct subfamily in species that are less well characterized and phylogenetic analysis is more difficult.

SnRK2s and SnRK3s are unique to plants, and have diverged further from SnRK1 than SnRK1 has from its fungal and animal counterparts, SNF1 and AMPK. Presumably the $S n R K 2$ and $S n R K 3$ genes first arose from duplications of the $S n R K 1$ gene, then evolved and diversified as they took on new roles, resulting in the burgeoning of the gene family as a whole. Our analysis revealed gene duplication (including segmental and tandem duplication) events in the evolution of the gene

Table 2 The KaKs values of the paired duplicated HvSnRK genes

\begin{tabular}{llll}
\hline Duplicated genes & Ka & Ks & Ka/Ks \\
\hline HvSnRK2.7/HvSnRK2.8 & 0.085723 & 1.474440 & 0.058139 \\
HvSnRK3.4/HvSnRK3.15 & 0.127287 & 1.294210 & 0.098351 \\
HvSnRK3.9/HvSnRK3.10 & 0.011528 & 0.024877 & 0.463405 \\
HvSnRK1.3/HvSnRK1.4 & 0.018936 & 0.035337 & 0.535865 \\
HvSnRK1.4/HvSnRK1.5 & 0.099710 & 0.245272 & 0.406528 \\
HvSnRK1.3/HvSnRK1.5 & 0.096129 & 0.245078 & 0.392240 \\
\hline
\end{tabular}

family, as well as differential regulation in response to ABA treatment. In addition, the $\mathrm{Ka} / \mathrm{Ks}$ analysis indicated that the duplicated $H v S n R K$ genes evolved slowly or were highly conserved [66].

SnRK1 genes of cereals have been subdivided into $S n R K 1 a$ and $S n R K 1 b$ according to their expression patterns, with SnRK1a expressed in multiple tissues and $S n R K 1 b$ expressed predominantly in the endosperm [1, $18,19]$. Curtis et al. [16] then identified a subclass similar to $S n R K 1 b$ that was expressed in the embryo as well as the endosperm and named it $S n R K 1 b *$ These three subclasses of $H v S n R K 1 s$ could be readily distinguished in the phylogenetic analysis in this study.

SnRK2s were also divided into two subclasses ( $\mathrm{a}$ and $\mathrm{b}$ ) by Halford and Hardie [1], then further into three subclasses (I, II and III) by Kobayashi et al. [33], with II/III corresponding to $S n R K 2 a$ and I to $S n R K 2 b$. Subclass II has been reported to be strongly activated by ABA, Class II weakly activated and Class I not at all [41-44]. The regulation of the barley $H \nu S n R K 2$ s by ABA appears to be more complicated. Phylogenetic analysis of the barley gene family readily distinguished the $H v S n R K 2 a$ Class II/III and HvSnRK1b Class I types; however, all but two of the HvSnRK2s (HvSnRK2.8 and HvSnRK2.10) had ABA response elements in their promoters, and those 

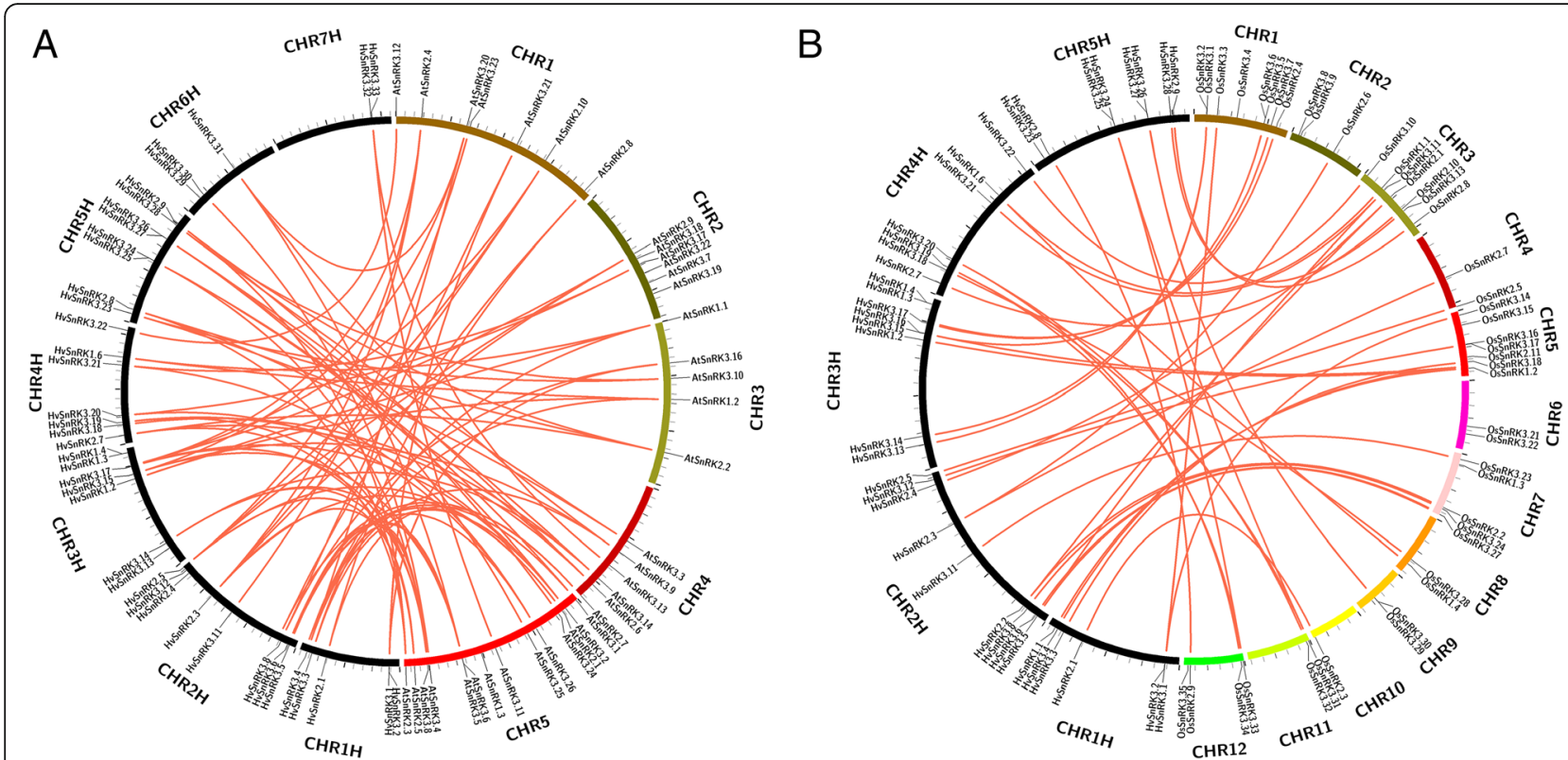

Fig. 5 Synteny analyses of SnRK genes between a. barley and Arabidopsis (Additional file 3. Sheet of synteny analysis 1); b. Barley and rice (Additional file 3. Sheet of synteny analysis 2). The genes linked by red lines represent homologues

that were shown to be significantly regulated by $\mathrm{ABA}$ treatment included members of all three subclasses.

Synteny analysis showed that one-to-one correspondence between the SnRKs of barley and rice was better than that between barley and Arabidopsis, consistent with the hypothesis of Wang et al. [60] that the monocot and dicot gene families have differentiated. The study also identified some $H \nu S n R K s$ without corresponding genes in either rice or Arabidopsis, indicating continued divergence and differentiation of the barley gene family since its evolutionary line split from that of rice.

\section{Conclusions}

The barley $H \nu S n R K$ gene family comprises $50 H v S n R K$ genes, six of which are of the HvSnRK1 subfamily, 10 $H v S n R K 2$ and 34 HvSnRK3. The presence/absence of specific motifs in the encoded proteins distinguishes between the subfamilies. Multiple putative regulatory elements are present in the gene promoters, with lightregulated elements (LRE), ABA response elements (ABRE) and methyl jasmonate response elements (MeJa) the most common. Many of the genes respond to ABA, some positively, some negatively and some with complex time-dependent responses.

\section{Methods}

Identification and phylogenetic analysis of the SnRK gene family in barley

The non-redundant amino acid sequences of Arabidopsis (Arabidopsis thaliana) and rice (Oryza sativa) SnRKs were collected from TAIR v10 (http://www. arabidopsis.org/) and RGAP v7 databases (http://rice. plantbiology.msu.edu/), respectively. Seventy-three SnRK sequences from Arabidopsis, 54 from rice and one (BKIN12) from barley were obtained directly from published papers [18, 36, 61, 62, 67] (Additional file 1). The entire predicted protein sequences of barley (Hordeum vulgare) were downloaded from the Ensembl Plants database (http://plants.ensembl.org/ Hordeum_vulgare/Info/Index, IBSC v2). To identify candidate SnRKs in Hordeum vulgare, local Hidden Markov Model-based searches in the protein sequence dataset were performed separately with PF00069 HMM. In addition, BLAST searches with all the published SnRK sequences of Arabidopsis, rice and barley as queries were performed to identify the predicted SnRKs in the Hordeum vulgare protein database. All the potential HvSnRK proteins identified from the HMM and BLAST searches were validated for the presence of conserved domains with the NCBI CDD databases (http://www.ncbi.nlm.nih.gov/cdd/) [68] and SMART web tools (http://smart.embl.de/) [69]. The conserved protein kinase (Pkinase) domain regions of the SnRK family from Arabidopsis, rice and barley were then selected to perform multiple alignments using MAFFT v7.427 [70]; this region was selected and the C-terminal region omitted because of the high variation in the C-terminal sequences of the SnRK proteins. The amino acid substitution model was calculated by the ProTest-3.4.2 and the optimal model of "JTT $+\mathrm{I}+\mathrm{G}+\mathrm{F}$ " was selected [71]. The RAxML v8.2.9 program was used to construct the 


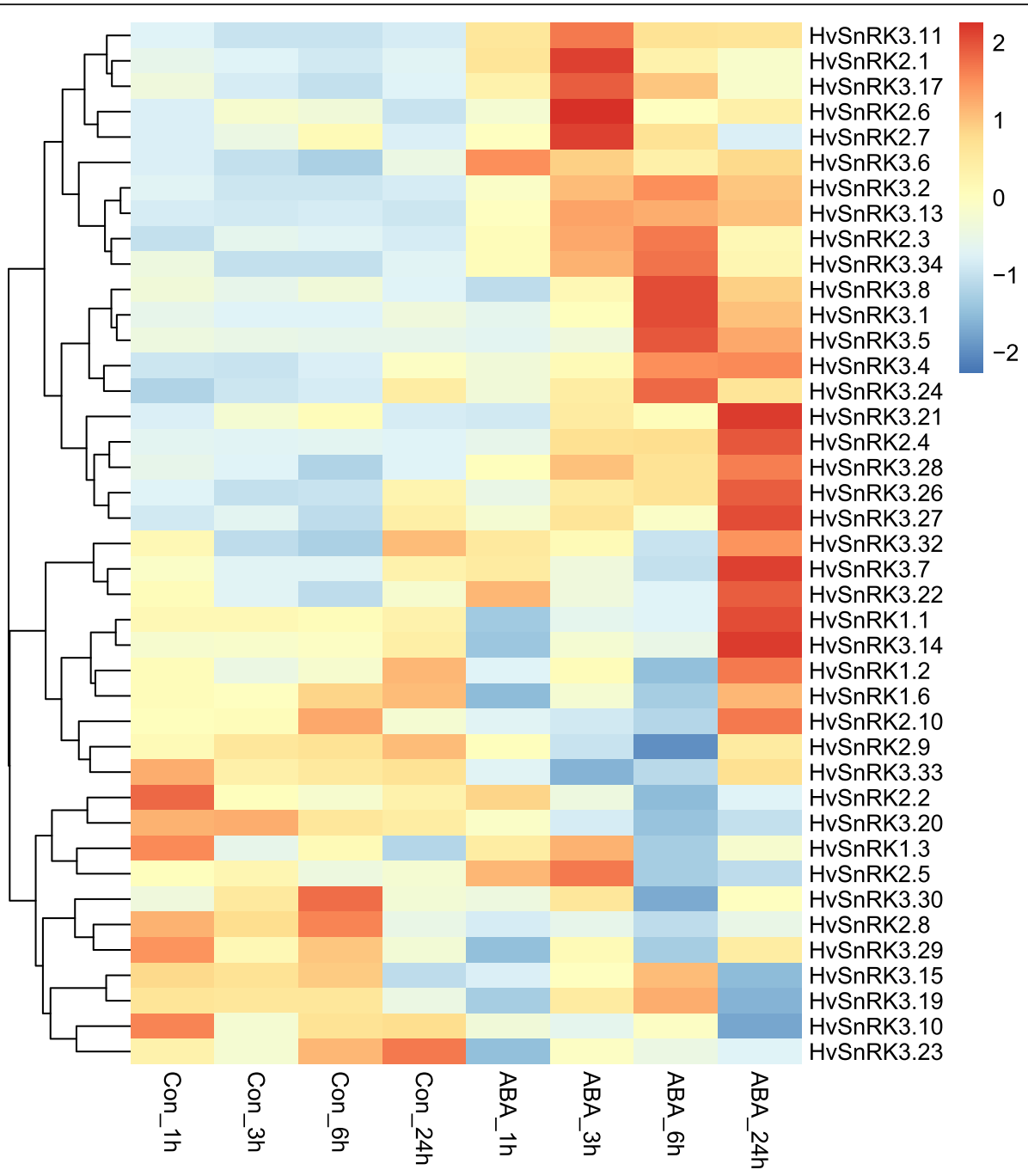

Fig. 6 Heatmap showing changes in expression of HVSnRK genes in response to ABA treatment in barley roots

maximum-likelihood (ML) tree, with bootstrap values for 1000 replicates [72], and FigTree was used to draw the rooted tree.

\section{Protein properties and sequence analyses}

The molecular weights and isoelectric points of putative HvSnRK proteins were calculated by the ExPASy proteomics server (http://expasy.org/). MEGA 7.0 was used for constructing an unrooted phylogenetic tree for the HvSnRK family proteins. In brief, all of the barley SnRK protein sequences were aligned using ClustalW with the default parameters, and the phylogenetic tree was built using the Neighbor-Joining (NJ) method within MEGA 7.0, with 1000 bootstrap replications. The MEME program (http://meme.sdsc.edu/meme/intro.html) was used to identify the motifs, and information on the $H v S n R K$ genes was obtained from the Hordeum vulgare genome database (Ensembl Plants). The gene structures and protein motifs were drawn by TB tools [73]. To analyze the cis-elements in the promoter regions, the $1.5 \mathrm{~kb}$ upstream region of the coding sequence region of each $H \nu S n R K$ gene (Additional file 1) was analyzed with the PlantCARE databases [74] (http://bioinformatics.psb. ugent.be/webtools/plantcare/html/), and the cis-elements were drawn by TB tools.

\section{Chromosomal location, genome synteny and gene duplication analyses}

The chromosomal location of the $H \nu \operatorname{SnRK}$ genes was downloaded from the Hordeum vulgare Genome Database (Ensembl Plants), and the distribution of the genes on chromosomes was drawn using the MG2C v.2 program (http://mg2c.iask.in/mg2c_v2.0/). Gene duplication, including segmental and tandem duplication, was analyzed using the MCScanX program [75]. Genes were considered to be segmentally duplicated if they occurred 
in collinear segments containing at least five collinear gene pairs, whereas they were considered to be tandemly duplicated if they were located close to each other with no more than two interval genes. The KaKs ratio (the ratio of nonsynonymous (Ka) to synonymous (Ks) nucleotide substitution rates) was also calculated for the duplicated gene pairs using the KaKs Calculator 2.0 [76].

\section{Plant materials and $A B A$ treatments}

Barley seeds of variety Morex (It was original from Jiangsu Coastal Area Institute of Agricultural Sciences, Jiangsu, China, and maintained at the Biotechnology Research Institute of Shanghai Academy of Agricultural Sciences by Chenghong Liu and Zhiwei Chen.) were sterilized with $1 \% \mathrm{NaClO}$ for $30 \mathrm{~min}$, and germinated in an incubator at $25^{\circ} \mathrm{C}$ for 4 days. Seedlings were transferred into plastic boxes within foam boards in them and cultured in nutrient solution mainly according to Chen et al. [73]. At the two to three-leaf stage, half of the seedlings were treated with $50 \mu \mathrm{M}$ ABA dissolved in ethanol and the other half were treated with ethanol alone. Roots were harvested separately at $1 \mathrm{~h}, 3 \mathrm{~h}, 6 \mathrm{~h}$ and $24 \mathrm{~h}$ after treatment, and samples were frozen in liquid nitrogen and keep at $-80^{\circ} \mathrm{C}$ until required. There were three biological replicates for each sample.

\section{cDNA library construction and RNA-sequencing}

Total RNA isolation and quality control were carried out according to Chen et al. [73], and $1.5 \mu \mathrm{g}$ total RNA per sample was used for RNA preparations. The NEBNext ${ }^{\circ}$ Ultra $^{\mathrm{Tx}}$ Directional RNA Library Prep Kit for Illumina (NEB, USA) was used to generate sequencing libraries, following the manufacturer's instructions, and mRNA was purified from total RNA using poly-Toligo-attached magnetic beads. Nucleotide sequence analysis of the libraries was then carried out on an Illumina Hiseq Xten platform (Illumina Inc., San Diego, CA), and $150 \mathrm{bp}$ paired-end reads were generated. The clean nucleotide sequence data ranged from 7.95 to $15.06 \mathrm{~Gb}$ (all $>6 \mathrm{~Gb}$ ), and the Q30 percentages were all $>80 \%$ (Table S1). These results suggested that the data were sufficient and reliable enough for further analysis. Spearman correlation analysis also showed that the three biological replicates of each sample met the requirements (all over 0.95) (Figure S1).

\section{Expression analysis of HvSnRKs by RNA-seq}

Reference genome and gene model annotation files were downloaded directly from the Ensembl plants database (http://plants.ensembl.org/Hordeum_vulgare/Info/Index, IBSC v2). An index of the reference genome was built and clean reads aligned to the reference genome using Hisat2 v2.0.5. HTSeq v0.6.1 was used to count the read numbers that mapped to each gene. The number of reads per kilobase of transcript, per million mapped reads (RPKM) was calculated based on the length of the gene and the number of reads that mapped to the gene. Differential expression analysis of the two treatments (with or without $\mathrm{ABA}$ ) was performed using the DESeq2 $\mathrm{R}$ package (1.16.1). Genes with a $p$ value $<0.05$ were assigned as significantly differentially-expressed

\section{Abbreviations}

SnRK: Sucrose nonfermenting-1-related protein kinase; ABA: Abscisic acid; LRE: Light-regulated elements; ABRE: ABA response elements; MeJa: Methyl jasmonate response elements; RNA-seq: RNA sequencing; SNF1: Sucrose non-fermenting 1; AMPK: AMP-activated protein kinase; SIP: SNF1 interacting protein; HMG-CoA: 3-hydroxy-3-methylglutaryl coenzyme A; ADP: Adenosine diphosphate; UDP: Uridine diphosphate; DON: Deoxynivalenol; VIGS: Virusinduced gene silencing; AREBP: ABA-response-element-binding protein; CBL: Calcineurin B-like protein; CIPK: CBL-interacting protein kinase; SOS: Salt overly sensitive

\section{Supplementary Information}

The online version contains supplementary material available at https://doi. org/10.1186/s12864-021-07601-6.

Additional file 1. SnRK peptides used for the blast, SnRK genes in Arabidopsis, rice and barley, and 1500 bp upstream nucleic acids sequences of HvSnRKS.

Additional file 2. Promoter predictions of HVSnRKS.

Additional file 3. Synteny analysis between Arabidopsis/rice and barley. Additional file 4. Up/down-regulated HvSnRKs genes response to ABA treatment.

Additional file 5: Figure S1. Spearman correlations of gene expressions among all samples.

Additional file 6: Figure S2. Amino acid sequences of the ten motifs for HvSnRK proteins. The larger the letters represent the higher ratio of the amino acid at each site.

Additional file 7: Table S1. Summary of RNA-seq data from barley roots treated with or without ABA at different time points (three biological replicates for each sample).

Acknowledgements

We also thank Mr. Chaoze Cheng for his help in searching of SnRK genes.

Authors' contributions

ZC and RL performed the plant growth, treatment and sample preparation; $\mathrm{LZ}$ and ZC performed the bioinformatics and data analysis of gene family related work; PJ and ZC performed the bioinformatics and statistical analyses of the RNA-seq data; ZC and NGH prepared the manuscript; NGH revised the manuscript; $C L$ designed the study. The author(s) read and approved the final manuscript.

\section{Funding}

This work was supported by the Shanghai Agriculture Applied Technology Development Program, China (Grant No. 2019-02-08-00-08-F01109), the Earmarked Fund for Modem Agro-industry Technology Research System (Grant No. CARS-05-01A-02), the Shanghai Academy of Agricultural Sciences: Program for Prominent Teams (Grant No. C2017B01) and Agricultural Science and Technology Innovation Program (Grant No. KJZC202008). NGH was supported at Rothamsted Research by the Biotechnology and Biological Sciences Research Council (BBSRC) of the UK via the Designing Future Wheat Programme (BB/P016855/1).

Availability of data and materials

The genome and gene annotation file of Arabidopsis (Arabidopsis thaliana), rice (Oryza sativa) SnRKs and barley (Hordeum vulgare) were collected from TAIR v10 (Peptide data: https://www.arabidopsis.org/download_files/ 
Sequences/TAIR10_blastsets/TAIR10_pep_20101214_updated; Annotation data: https://www.arabidopsis.org/download_files/Genes/TAIR10_genome_ release/TAIR10_gff3/TAIR10_GFF3_genes.gff; Genome data: https://www. arabidopsis.org/download_files/Genes/TAIR10_genome_release/TAIR10_ chromosome_files/TAIR10_chr_all.fas.), RGAP V7 databases (Peptide data: http://rice.plantbiology.msu.edu/pub/data/Eukaryotic_Projects/o_sativa/ annotation_dbs/pseudomolecules/version_7.0/all.dir/all.pep; Annotation data: http://rice.plantbiology.msu.edu/pub/data/Eukaryotic_Projects/o_sativa/ annotation_dbs/pseudomolecules/version_7.0/all.dir/all.gff3; Genome data: http://rice.plantbiology.msu.edu/pub/data/Eukaryotic_Projects/o_sativa/ annotation_dbs/pseudomolecules/version_7.0/all.dir/all.con .) and the Ensembl Plants database (Peptide data: ftp://ftp.ensemblgenomes.org/pub/ plants/release-50/fasta/hordeum_vulgare/pep/Hordeum_vulgare.IBSC_v2.pep. all.fa.gz; Annotation data: ftp://ftp.ensemblgenomes.org/pub/plants/release-5 0/gtf/hordeum_vulgare/Hordeum_vulgare.IBSC_v2.50.gtf.gz; Genome data: ftp://ftp.ensemblgenomes.org/pub/plants/release-50/fasta/hordeum_vulgare/ dna/Hordeum_vulgare.IBSC_v2.dna_sm.toplevel.fa.gz .), respectively. The RNA-seq data have been deposited with the National Center for Biotechnology Information: BioProject ID PRJNA661163.

\section{Declarations}

\section{Ethics approval and consent to participate}

Not applicable.

\section{Consent for publication}

Not applicable.

\section{Competing interests}

None to declare

\section{Author details}

Biotechnology Research Institute, Shanghai Academy of Agricultural Sciences, Shanghai 201106, China. ${ }^{2}$ Shanghai Key Laboratory of Agricultural Genetics and Breeding, Shanghai 201106, China. ${ }^{3}$ Shenzhen RealOm ics (Biotech) Co., Ltd., Shenzhen 518081, China. ${ }^{4}$ Plant Sciences Department, Rothamsted Research, Harpenden, Hertfordshire AL5 2JQ, UK.

\section{Received: 29 October 2020 Accepted: 11 April 2021}

\section{Published online: 26 April 2021}

\section{References}

1. Halford NG, Hardie DG. SNF1-related protein kinases: global regulators of carbon metabolism in plants? Plant Molec Biol. 1998;37(5):735-48. https:// doi.org/10.1023/A:1006024231305.

2. Halford NG, Hey SJ. Snf1-related protein kinases (SnRKs) act within an intricate network that links metabolic and stress signalling in plants. Biochem J. 2009;419(2):247-59. https://doi.org/10.1042/BJ20082408.

3. Hey SJ, Byrne E, Halford NG. The interface between metabolic and stress signalling. Ann Bot. 2010;105(2):197-203. https://doi.org/10.1093/aob/mcp2 85.

4. Alderson A, Sabelli PA, Dickinson JR, Cole D, Richardson M, Kreis M, et al. Complementation of snf1, a mutation affecting global regulation of carbon metabolism in yeast, by a plant protein kinase CDNA. Proc Natl Acad Sci U S A. 1991;88(19):8602-5. https://doi.org/10.1073/pnas.88.19.8602.

5. Tiessen A, Prescha K, Branscheid A, Palacios N, McKibbin R, Halford NG, et al. Evidence that SNF1-related kinase and hexokinase are involved in separate sugar-signalling pathways modulating post-translational redox activation of ADP-glucose pyrophosphorylase in potato tubers. Plant J. 2003;35(4):490500. https://doi.org/10.1046/j.1365-313X.2003.01823.x

6. Baena-González E, Rolland F, Thevelein JM, Sheen J. A central integrator of transcription networks in plant stress and energy signalling. Nature. 2007; 448(7156):938-42. https://doi.org/10.1038/nature06069.

7. Schwachtje J, Minchin PEH, Jahnke S, van Dongen JT, Schittko U, Baldwin IT. SNF1-related kinases allow plants to tolerate herbivory by allocating carbon to roots. Proc Natl Acad Sci U S A. 2006;103(34):12935-40. https://doi.org/1 0.1073/pnas.0602316103

8. Purcell PC, Smith AM, Halford NG. Antisense expression of a sucrose nonfermenting-1-related protein kinase sequence in potato results in decreased expression of sucrose synthase in tubers and loss of sucrose- inducibility of sucrose synthase transcripts in leaves. Plant J. 1998;14(2):195202. https://doi.org/10.1046/j.1365-313X.1998.00108.x.

9. McKibbin RS, Muttucumaru N, Paul MJ, Powers SJ, Burrell MM, Coates S, et al. Production of high starch, low glucose potatoes through overexpression of the metabolic regulator, SnRK1. Plant Biotech J. 2006:4(4):40918. https://doi.org/10.1111/j.1467-7652.2006.00190.x.

10. Kanegae H, Miyoshi K, Hirose T, Tsuchimoto S, Mori M, Nagato Y, et al. Expressions of rice sucrose non-fermenting-1 related protein kinase 1 genes are differently regulated during the caryopsis development. Plant Physiol Biochem. 2005;43(7):669-79. https://doi.org/10.1016/j.plaphy.2005.06.004.

11. Jain M, Li Q-B, Chourey PS. Cloning and expression analyses of sucrose nonfermenting-1-related kinase 1 (SnRK1b) gene during development of sorghum and maize endosperm and its implicated role in sugar-to-starch metabolic transition. Physiol Plantarum. 2008;134(1):161-73. https://doi.org/1 0.1111/j.1399-3054.2008.01106.x.

12. Zhang $Y$, Shewry PR, Jones H, Barcelo P, Lazzeri PA, Halford NG. Expression of antisense SnRK1 protein kinase sequence causes abnormal pollen development and male sterility in transgenic barley. Plant J. 2001;28:431-42.

13. Arad M, Benson DW, Perez-Atayde AR, McKenna WJ, Sparks EA, Kanter RJ et al. Constitutively active AMP kinase mutations cause glycogen storage disease mimicking hypertrophic cardiomyopathy. J Clin Invest. 2002;109(3): 357-62. https://doi.org/10.1172/JCl0214571.

14. Hardy TA, Huang D, Roach PJ. Interactions between CAMP-dependent and SNF1 protein kinases in the control of glycogen accumulation in Saccharomyces cerevisiae. J Biol Chem. 1994;269(45):27907-13. https://doi. org/10.1016/S0021-9258(18)46873-1.

15. Laurie S, McKibbin RS, Halford NG. Antisense SNF1-related (SnRK1) protein kinase gene represses transient activity of an a-amylase ( $a$-Amy2) gene promoter in cultured wheat embryos. J Exp Bot. 2003;54(383):739-47. https://doi.org/10.1093/jxb/erg085.

16. Curtis TY, Raffan S, Wan Y, King R, Gonzalez-Uriarte A, Halford NG. Contrasting gene expression patterns in grain of high and low asparagine wheat genotypes in response to Sulphur supply. BMC Genomics. 2019;20(1): 628. https://doi.org/10.1186/s12864-019-5991-8.

17. Raffan S, Oddy J, Halford NG. The Sulphur response in wheat and its implications for acrylamide formation and food safety. Int J Molec Sci. 2020; 21(11):3876. https://doi.org/10.3390/ijms21113876.

18. Halford NG, Vicente-Carbajosa J, Sabelli PA, Shewry PR, Hannappel U, Kreis M. Molecular analyses of a barley multigene family homologous to the yeast protein kinase gene SNF1. Plant J. 1992;2(5):791-7.

19. Hannappel U, Vicente-Carbajosa J, Barker JHA, Shewry PR, Halford NG. Differential expression of two barley SNFI-related protein kinase genes. Plant Molec Biol. 1995:27:235-1240.

20. Hulsmans S, Rodriguez M, De Coninck B, Rolland F. The SnRK1 energy sensor in plant biotic interactions. Trends Plant Sci. 2016;21(8):648-61. https://doi.org/10.1016/j.tplants.2016.04.008.

21. Margalha L, Confraria A, Baena-Gonzalez E. SnRK1 and TOR: modulating growth-defense trade-offs in plant stress responses. J Exp Bot. 2019;70(8): 2261-74. https://doi.org/10.1093/jxb/erz066.

22. Shen Q, Liu Z, Song F, Xie Q, Hanley-Bowdoin L, Zhou X. Tomato SISnRK1 protein interacts with and phosphorylates $\beta C 1$, a pathogenesis protein encoded by a Geminivirus $\beta$-satellite. Plant Physiol. 2011;157:394-1406.

23. Seo YS, Chern M, Bartley LE, Han M, Jung KH, Lee I, et al. Towards establishment of a rice stress response interactome. PLoS Genet. 2011;7: e1002020.

24. Filipe O, De Vleesschauwer D, Haeck A, Demeestere K, Hofte M. The energy sensor OsSnRK1a confers broad-spectrum disease resistance in rice. Sci Rep. 2018;8(1):3864. https://doi.org/10.1038/s41598-018-22101-6.

25. Perochon A, Váry Z, Malla KB, Halford NG, Paul MJ, Doohan FM. The wheat SnRK1a family and its contribution to Fusarium toxin tolerance. Plant Sci. 2019;288:110217. https://doi.org/10.1016/j.plantsci.2019.110217.

26. Sugden C, Donaghy P, Halford NG, Hardie DG. Two SNF1-related protein kinases from spinach leaf phosphorylate and inactivate 3-hydroxy-3methylglutaryl-coenzyme a reductase, nitrate reductase and sucrose phosphate synthase in vitro. Plant Physiol. 1999;120(1):257-74. https://doi. org/10.1104/pp.120.1.257.

27. Ball KL, Barker JHA, Halford NG, Hardie DG. Immunological evidence that HMG-CoA reductase kinase-a is the cauliflower homologue of the RKIN1 subfamily of plant protein kinases. FEBS Letts. 1995;377(2):189-92. https:// doi.org/10.1016/0014-5793(95)01343-1. 
28. Barker JHA, Slocombe SP, Ball KL, Hardie DG, Shewry PR, Halford NG. Evidence that barley 3-hydroxy-3-methylglutaryl-coenzyme a reductase kinase is a member of the sucrose nonfermenting-1-related protein kinase family. Plant Physiol. 1996;112(3):1141-9. https://doi.org/10.1104/ pp.112.3.1141

29. Crawford RM, Halford NG, Hardie DG. Cloning of DNA encoding a catalytic subunit of SNF1-related protein kinase-1 (SnRK1-a1) and immunological analysis of multiple forms of the kinase in spinach leaf. Plant Molec. Biol. 2001;45(6):731-41. https://doi.org/10.1023/A:1010600603276.

30. Anderberg RJ, Walker-Simmons MK. Isolation of a wheat CDNA clone for an abscisic acid-inducible transcript with homology to protein kinases. PNAS. 1992:89(21):10183-7. https://doi.org/10.1073/pnas.89.21.10183.

31. Holappa LD, Walker-Simmons MK. The wheat abscisic acid-responsive protein kinase mRNA, PKABA1, is up-regulated by dehydration, cold temperature, and osmotic stress. Plant Physiol. 1995;108(3):1203-10. https:// doi.org/10.1104/pp.108.3.1203.

32. Lou D, Wang H, Liang G, Yu D. OsSAPK2 confers abscisic acid sensitivity and tolerance to drought stress in rice. Frontiers Plant Sci. 2017;8:993. https://doi. org/10.3389/fpls.2017.00993.

33. Kobayashi $Y$, Yamamoto S, Minami H, Kagaya Y, Hattori T. Differential activation of the rice sucrose nonfermenting1-related protein kinase2 family by hyperosmotic stress and abscisic acid. Plant Cell. 2004;16(5):1163-77. https://doi.org/10.1105/tpc.019943.

34. Cutler SR, Rodriguez PL, Finklestein RR, Abrams SR. Abscisic acid: emergence of a core signaling network. Ann Rev Plant Biol. 2010;61(1):651-79. https:// doi.org/10.1146/annurev-arplant-042809-112122

35. Liu Z, Ge X, Yang Z, Zhang C, Zhao G, Chen E, et al. Genome-wide identification and characterization of SnRK2 gene family in cotton (Gossypium hirsutum L.). BMC Genet. 2017;18(1):54. https://doi.org/10.1186/ s12863-017-0517-3.

36. Hrabak EM, Chan CWM, Gribskov M, Harper JF, Choi JH, Halford NG, et al. The Arabidopsis CDPK-SnRK superfamily of protein kinases. Plant Physiol. 2003;132(2):666-80. https://doi.org/10.1104/pp.102.011999.

37. Kobayashi Y, Murata M, Minami H, Yamamoto S, Kagaya Y, Hobo T, et al. Abscisic acid-activated SnRK2 protein kinases function in the generegulation pathway of $A B A$ signal transduction by phosphorylating $A B A$ response element-binding factors. Plant J. 2005;44(6):939-49. https://doi. org/10.1111/j.1365-313X.2005.02583.x.

38. Umezawa T, Nakashima K, Miyakawa T, Kuromori T, Tanokura M, Shinozaki K, et al. Molecular basis of the core regulatory network in ABA responses: sensing, signaling and transport. Plant Cell Physiol. 2010;51(11):1821-39. https://doi.org/10.1093/pcp/pcq156.

39. Soon FF, Ng LM, Zhou XE, West GM, Kovach A, Tan MH, et al. Molecular mimicry regulates ABA signaling by SnRK2 kinases and PP2C phosphatases. Science. 2012;335(6064):85-8. https://doi.org/10.1126/science.1215106.

40. Zhang Y, Andralojc PJ, Hey SJ, Primavesi LF, Specht M, Koehler J, et al. Arabidopsis SNF1-related protein kinase-1 and calcium-dependent protein kinase phosphorylate conserved target sites in ABA response element binding proteins. Ann Appl Biol. 2008;153(3):401-9. https://doi.org/10.1111/ j.1744-7348.2008.00302.x.

41. Yoshida R, Umezawa T, Mizoguchi T, Takahashi S, Takahashi F, Schinozaki K. The regulatory domain of SRK2E/OST1/SnRK2.6 interacts with ABI1 and integrates $\mathrm{ABA}$ and osmotic stress signals controlling stomatal closure in Arabidopsis. J Biol Chem. 2006;281(8):5310-8. https://doi.org/10.1074/jbc. M509820200.

42. Nakashima K, Fujita Y, Kanamori N, Katagiri T, Umezawa T, Kidokor S, et al. Three Arabidopsis SnRK2 protein kinases, SRK2D/SnRK2.2, SRK2E/SnRK2.6/ OST1 and SRK2I/SnRK2.3, involved in ABA signaling are essential for the control of seed development and dormancy. Plant Cell Physiol. 2009;50(7): 1345-63. https://doi.org/10.1093/pcp/pcp083.

43. Fujii $H$, Chinnusamy V, Rodrigues A, Rubio S, Antoni R, Park S, et al. In vitro reconstruction of an abscisic acid signaling pathway. Nature. 2009;462(7273): 660-4. https://doi.org/10.1038/nature08599.

44. Kulik A, Wawer I, Krzywinska E, Bucholc M, Dobrowolska G. SnRK2 protein kinases - key regulators of plant response to abiotic stresses. OMICS. 2011; 15(12):859-72. https://doi.org/10.1089/omi.2011.0091.

45. Wilkinson S, Davies WJ. ABA-based chemical signalling: the co-ordination of responses to stress in plants. Plant, Cell and Env. 2002;25(2):195-210. https:// doi.org/10.1046/j.0016-8025.2001.00824.x.

46. Sreenivasulu N, Radchuk V, Strickert M, Miersch O, Weschke W, Wobus U. Gene expression patterns reveal tissue-specific signalling networks controlling programmed cell death and ABA-regulated maturation in developing barley seeds. Plant J. 2006;47(2):310-27. https://doi.org/10.1111/ j.1365-313X.2006.02789.x.

47. Coello P, Hirano E, Hey SJ, Muttucumaru N, Martinez-Barajas E, Parry MJ. Halford NG evidence that ABA promotes degradation of SNF1-related protein kinase (SnRK) 1 in wheat and activation of a putative calciumdependent SnRK2. J Exp Bot. 2012;63(2):913-24. https://doi.org/10.1093/jxb/ err320.

48. Chen Z, Muttucumaru N, Powers SJ, Halford NG. Expression analysis of abscisic acid (ABA) and metabolic signalling factors in developing endosperm and embryo of barley. J Cereal Sci. 2013;58(2):255-62. https:// doi.org/10.1016/j.jcs.2013.06.009.

49. Sano H, Youssefian S. Light and nutritional regulation of transcript encoding a wheat protein kinase homolog is mediated by cytokinins. Proc Natl Acad Sci U S A. 1994;91(7):2582-6. https://doi.org/10.1073/pnas.91.7.2582.

50. Ikeda Y, Koizumi N, Kusano T, Sano H. Sucrose and cytokinin modulation of WPK4, a gene encoding a SNF1-related protein kinase from wheat. Plant Physiol. 1999;121(3):813-20. https://doi.org/10.1104/pp.121.3.813.

51. Halfter U, Ishitani M, Zhu JK. The Arabidopsis SOS2 protein kinase physically interacts with and is activated by the calcium-binding protein SOS3. Proc Natl Acad Sci U S A. 2000;97(7):3735-40. https://doi.org/10.1073/pnas.97.7.3735.

52. Gong D, Guo Y, Schumaker KS, Zhu J-K. Update on calcium and protein kinase signalling: the SOS3 family of calcium sensors and SOS2 family of protein kinases in Arabidopsis. Plant Physiol. 2004;134(3):919-26. https://doi. org/10.1104/pp.103.037440.

53. Guo Y, Xiong L, Song C-P, Gong D, Halfter U, Zhu J-K. A calcium sensor and its interacting protein kinase are global regulators of abscisic acid signaling in Arabidopsis. Dev Cell. 2002;3(2):233-44. https://doi.org/10.1016/S15345807(02)00229-0.

54. Kudla J, Xu Q, Harter K, Gruissem W, Luan S. Genes for calcineurin B-like proteins in Arabidopsis are differentially regulated by stress signals. Proc Natl Acad Sci U S A. 1999;96(8):4718-23. https://doi.org/10.1073/pnas.96.8.4 718.

55. Shi J, Kim K-N, Ritz O, Albrecht V, Gupta R, Harter K, et al. Novel protein kinases associated with calcineurin B-like calcium sensors in Arabidopsis. Plant Cell. 1999;11(12):2393-405. https://doi.org/10.1105/tpc.11.12.2393.

56. Kim K-N, Cheong YH, Gupta R, Luan S. Interaction specificity of Arabidopsis calcineurin B-like calcium sensors and their target kinases. Plant Physiol. 2000;124(4):1844-53. https://doi.org/10.1104/pp.124.4.1844.

57. Liu J, Ishitani M, Halfter U, Kim C, Zhu J. The Arabidopsis thaliana SOS2 gene encodes a protein kinase that is required for salt tolerance. PNAS. 2000; 97(7):3730-4. https://doi.org/10.1073/pnas.97.7.3730.

58. Tang R-J, Wang C, Li K, Luan S. The CBL-CIPK calcium signaling network: unified paradigm from 20 years of discoveries. Trends Plant Sci. 2020;25(6): 604-17. https://doi.org/10.1016/j.tplants.2020.01.009.

59. Ma X, Li QH, Yu YN, Qiao YM, Haq SU, Gong ZH. The CBL-CIPK pathway in plant response to stress signals. Int J Mol Sci. 2020;21(16):5668. https://doi. org/10.3390/ijms21165668.

60. Wang L, Hu W, Sun J, Liang X, Yang X, Wei S, et al. Genome-wide analysis of SnRK gene family in Brachypodium distachyon and functional characterization of BdSnRK2.9. Plant Sci. 2015;237:33-45. https://doi.org/10.1 016/j.plantsci.2015.05.008.

61. Wu P, Wang W, Duan W, Li Y, Hou X. Comprehensive analysis of the CDPKSnRK superfamily genes in Chinese cabbage and its evolutionary implications in plants. Front Plant Sci. 2017:8:162.

62. Zhao W, Cheng YH, Zhang C, Shen XJ, You QB, Guo W, et al. Genome-wide identification and characterization of the GmSnRK2 family in soybean. Int J Mol Sci. 2017;18(9):1834. https://doi.org/10.3390/ijms18091834.

63. Zhu W, Wu D, Jiang L, Ye L. Genome-wide identification and characterization of SnRK family genes in Brassica napus. BMC Plant Biol. 2020;20(1):287. https://doi.org/10.1186/s12870-020-02484-3.

64. Albrecht V, Ritz O, Linder S, Harter K, Kudla J. The NAF domain defines a novel protein-protein interaction module conserved in $\mathrm{Ca}^{2+}$-regulated kinases. EMBO J. 2001;20(5):1051-63. https://doi.org/10.1093/emboj/20.5.1 051.

65. Wurzinger B, Nukarinen E, Nägele T, Weckwerth W, Teige M. The SnRK1 kinase as central mediator of energy signaling between different organelles. Plant Physiol. 2018;176(2):1085-94. https://doi.org/10.1104/pp.17.01404.

66. Shen S, Zhang Q, Shi Y, Sun Z, Zhang Q, Hou S, et al. Genome-wide analysis of the NAC domain transcription factor gene family in Theobroma cacao. Genes (Basel). 2020;11(1):35. 
67. Kolukisaglu Ü, Weinl S, Blazevic D, Batistic O, Kudla J. Calcium sensors and their interacting protein kinases: genomics of the Arabidopsis and rice CBLCIPK signaling networks. Plant Physiol. 2004;134(1):43-58. https://doi.org/1 0.1104/pp.103.033068

68. Marchler-Bauer A, Bo Y, Han L, He J, Lanczycki CJ, Lu S, et al. CDD/SPARCLE: functional classification of proteins via subfamily domain architectures. Nucleic Acids Res. 2017;45(D1):D200-3. https://doi.org/10.1093/nar/gkw1129.

69. Letunic I, Copley RR, Schmidt S, Ciccarelli FD, Doerks T, Schultz J, et al. SMART 4.0: towards genomic data integration. Nucl. Acids Res. 2004;32(1): D142-4. https://doi.org/10.1093/nar/gkh088.

70. Katoh K, Standley DM. MAFFT multiple sequence alignment software version 7: improvements in performance and usability. Mol Biol Evol. 2013; 30(4):772-80. https://doi.org/10.1093/molbev/mst010.

71. Darriba D, Taboada GL, Doallo R, Posada D. ProtTest 3: fast selection of bestfit models of protein evolution. Bioinformatics. 2011;27(8):1164-5. https:// doi.org/10.1093/bioinformatics/btr088.

72. Stamatakis A. RAxML version 8: a tool for phylogenetic analysis and postanalysis of large phylogenies. Bioinformatics. 2014;30(9):1312-3. https://doi. org/10.1093/bioinformatics/btu033.

73. Chen C, Chen H, Zhang Y, Thomas HR, Frank MH, He Y, et al. TBtools: an integrative toolkit developed for interactive analyses of big biological data. Mol Plant. 2020;13(8):1194-202. https://doi.org/10.1016/j.molp.2020.06.009.

74. Lescot M, Déhais P, Thijs $G$, Marchal $K$, Moreau Y, Van de Peer Y, et al. PlantCARE, a database of plant cis-acting regulatory elements and a portal to tools for in silico analysis of promoter sequences. Nucl Acids Res. 2002; 30(1):325-7. https://doi.org/10.1093/nar/30.1.325.

75. Wang Y, Tang H, DeBarry JD, Tan X, Li J, Wang X, et al. MCScanX: a toolkit for detection and evolutionary analysis of gene synteny and collinearity. Nucl. Acids Res. 2012;40(7):e49. https://doi.org/10.1093/nar/gkr1293.

76. Wang D, Zhang Y, Zhang Z, Zhu J, Yu J. KaKs_Calculator 2.0: a toolkit incorporating gamma-series methods and sliding window strategies. Genomics Proteomics Bioinformatics. 2010;8(1):77-80. https://doi.org/10.101 6/S1672-0229(10)60008-3

\section{Publisher's Note}

Springer Nature remains neutral with regard to jurisdictional claims in published maps and institutional affiliations.

Ready to submit your research? Choose BMC and benefit from:

- fast, convenient online submission

- thorough peer review by experienced researchers in your field

- rapid publication on acceptance

- support for research data, including large and complex data types

- gold Open Access which fosters wider collaboration and increased citations

- maximum visibility for your research: over $100 \mathrm{M}$ website views per year

At $\mathrm{BMC}$, research is always in progress.

Learn more biomedcentral.com/submissions 